the end of a week we had a long talk, and that night I determined to make more effort. . . . Then about walking, I was not told at all what I was to do, only I knew he thought I should do a little more each day. ... I got the strength during the laying on of hands, bat I did not have generally any particular feelings at the time. . . The gift of healing is only given to some.

These extracts are best left without comment, but clearly they prove both the great responsibility assumed in making such promiscuous attempts at healing, and the sort of belief instilled into the members. The obvious impropriety of such treatment for myasthenia gravis makes it unnecessary to add that no "healing" was accomplished.

Recently I was able to refer to the methods of this guild at a conference on spiritual healing, held in the parish room of a city church, when Mr. Boyd was fortunately present. After the meeting Mr. Boyd sought to justify his actions by explaining to me that when possible he always consulted medical men and that he gave no directions to this lady to overexert herself! The sister of this lady tells me that the organizing secretary of this guild wrote to her:

We don't consider any disease, however incurable it seems, to be beyond the reach of spiritual healing.

On asking Mr. Boyd if he endorsed this statement he replied, "Theoretically, yes ; practically, no," which is a somewhat important difference when it is a question of dealing with such a disease as myasthenia gravis.

At this meeting Mr. Boyd finished his speech by remark. ing that if he chose to carry on spiritual healing he saw no reason why he should not do so. We might be more likely to agree if Mr. Boyd either worked quietly in his capacity as a clergyman, under proper conditions in conjunction with medical men, or else dissociated himself from the Church and openly called himself a spiritual healer. But, while holding a responsible position in the Church of England, to have his name spread broadcast as a spiritual healer, by being warden of this guild, is at variance not only with the example set by our Great Teacher but with the best traditions of the noble profession to which he belongs.

I make the following extracts from a printed publication, issued by the guild and written by its warden, to show the chief tenets of this society:

I do not think that as a guild we are concerned with theories as to precisely how health is preserved or recovered.

Nothing surely could be further from our Lord's mind than to "make a splash" by a thaumaturgical display. The Gospel had no need of the assistance of such methods. Besides, there is not the smallest hint that our Lord ever intended these gifts to be temporary. And also, this "gift" of healing was no " miraculous" gift in the sense of being an arbitrary permission to break natural laws. Healing is the operation of law, not the breaking of it. It is merely an instance of what we see every day-a higher law superseding a lower one. And precisely because it is a law it is not temporary, and under the same conditions the same results must follow to-day.... We must conclude, then, that the gift of healing once given is still in the Church, and ought to be used by those who are so called by the Holy Spirit. ... For practical purposes we treat disesse (quite rightly) as an evil thing, proceeding rather from Satan than from God, a thing to be by every means opposed and done away with; and our only regret is that we cannot more successfally and completely abolish the evil thing.

Of course, it is no reply in favour of this guild to quote instances of some of its other cases which have been benefited. Naturally, this would occur with certain illnesses, but does not affect the argument against the whole principle and method of procedure adopted by the guild in its conduct of spiritual healing.

I hope I have said enough to make us give a wide berth to this guild or to any similar society that may spring up in the future. I offer this criticism becsuse such societies can only tend to retard that most desirable greater union of religion and medicine in a combined attempt to help the physical and mental health of mankind. If our profession has been backward in the past in securing the great help often obtainable from ministers of religion, yet the latter should not approve of attracting men and women to undergo "spiritual healing" by their colleagues through the medium of any such society as the Guild of Health.

\section{THE CATHOLIC CHURCH AND THE LOURDES} CURES.

By the Right Rev. Francis Aidan Gasquet, D.D, Abbot President of the English Benedictines.

THe articles which have appeared in the British Mrdical Journal on "Faith Healing" and the "Louraes Miracles" seem to call for some remarks from a Catholic standpoint. I welcome this remarkable series of papers, written by the most eminent men of the medical profession, for their spirit of fairness, although they are for the most part written from a strictly rationalistic point of view. As I conceive it, the fundamental difference between the Catholic and the non-Catholic attitude towards " miracles" in general, is in regard to the possibility of such interventions on the part of the Supreme Being. We affirm not only the possibility but the fact that God has wrought miracles on earth all throughout its history and even since the days of the apostles. Whether He has done so or not in any given case is for us merely a question of evidence.

A miracle, as we understand it, is something which is above or contrary to the ordinary known laws of Nature, or something brought about by supernatural agency. We believe not only that God has made the world and established the laws which govern it, but that His Almighty power continues to rule and control it by $\mathrm{His}$ direct action npon it. No one who believes in the existence of God can reasonably doubt the possibility of miracles. To question it is to question whether the Supreme Being can depart from the laws which $\mathrm{He}$ has established as Maker of heaven and earth. Jean Jacques Rousseau, that typical unbeliever, long ago declared that such a question "would be impious if it were not absurd," and added that "no man ever denied that God could work miracles." Renan, too, formulated the same idea when he said that the verse of the Paalmist, Numquid poterit Deus parare mensam in deserto, was a fallacy of interrogation, since it was not a question of God's power to feed His people in the desert, but of His will to do so.

Miracles, then, to the Catholics are historical facts, and they depend, as all other historical facts, upon the evidence. In his Apoiogia Cardinal Newman points out that Catholics hold that what God has done once He can and indeed is likely to do again. On the other hand, those who hold that the age of miracles is past argue that what the Supreme Being had indeed once done He is not likely to do again. According, therefore, to his principles, the occurrence of supernatural facts-miracles-does not startle the Cathoiic. They may or may not have taken place; he may have no distinct evidence; he may suspend his judgement, but he will say, "It is very possible." He will never say, "I cannot believe it."

So much it is necessary to state as to the attitude of mind in which a Catholic approaches the examination of some so.called miraculous event. And, although the fundamental belief that God can and sometimes does work in a miraculous way may dispose him to accept the fact as being supernatural, his actual acceptance is and should be strictly scientific and based upon the evidence. He has to satisfy himself on the three points: (1) Is it antecedently probable? (2) Is it in its nature certainly miraculous? (3) Has it sufficient evidence?

It is difficult to see what objection can be reasonably raised against the attitude of the Catholic Church towards the miraculous. It is entirely judicious, and does not accept mere credulity. In the process of canonization the official rules of evidence leave nothing to be desired, in the opinion of non. Catholic lawyers who have examined thom. The supernatural character of facts alleged as miracles is tested by every possible means; the evi. dence is sifted with minute care, and facts reputed to be miraculous are rejected which do not fully stand the required tests. The principles adopted by the Congregation of Rites in this examination are those laid down by Pope Benedict XIV, and are worth setting forth in some detail.

Four proved miracles are required for Beatification and two more for Canonization. These must be attested by eye and not by ear witnesses.

For an alleged cure to be received as miraculous, it is requisite (1) that the disease cured must have been of an aggravated nature, difficult or impossible to be cured in 
the ordinary way; (2) that the condition of the patient before the cure showed no signs of mending; (3) that no medicine had been used, or that if it had, that it had done no good; (4) that the cure was sudden; (5) that the cure was complete; and (6) that it was permanent. Could the official attitude of the Church towards miracles be more cautious?

Let me take the case of the recovery of a person's sight, which is proposed to the congregation as a miraculous cure. First of all, it has to be proved that the person was born blind, or had become so afterwards under stated circumstances; secondly, the duration of the blindness has to be stated ; thirdly, the cure has to be most minutely detailed ; fourthly, the written opinions of the best scientific and medical men as to the cause, etc., of the blindness, must be forthcoming ; fifthly, it must be shown that it is impossible to refer the cure to known natural causes; sixthly, it is necessary to show that the cure was instantaneous, which is always required in regard to miracles of the first class; seventhly, whenever the physicians and scientific men cannot trace the absolute cause of blindness, no definite judgement is ever given.

Acting strictly on these rules, a great number of alleged miracles are absolutely rejected in the process of examina tion into the sanctity of some eminent servant of God. For example, in the case of St. Peter Fournier, the miracalous character of several cures supposed to be wrought through his help was denied, because they were not instan. taneous and because it was not shown that the cure could not have been effected by natural causes. In the case of St. Stanislaus, the instantaneous stoppage of a haemorrhage, which was adduced as a cure through his intercession, was not allowed to be miraculous, because, according to the laws of the science of medicine, so much blood had been lost by the patient that be ought to have died before the saint was invoked. Out of nine facts adduced as miraculous in the cause of St. Camillus two only were allowed. This may, I think, be taken as suffi. cient evidence of the stringent and scientific way in which any question of the miraculous is approached by the Catholic Church.

What is true of the attitude of the authorities of the Roman Congregation towards alleged miraculous facts is true in regard to what are known as "Lourdes miracles." The utmost care is taken to examine into each case; to secure the full medical history of the patient; and, as far as possible, to follow the course of events subsequent to the alleged cure. In the majority of cases cured at Lourdes it is admitted that the relief from suffering or the restoration of health is due to the influence of mind over body, or as we prefer to call it, to the religious influences of the place, including of course the result of a belief in the intercession of the Blessed Mother of God to obtain the cure of the sufferer. That such a cure, which could not, or was not able to be obtained otherwise, did in fact take place under such influences, is surely sufficient to claim that it is a grace, a providence; a manifestation wrought by the ethos of the place and by the deep religious feelings called forth in the mind by it. To attribute it to the influence of the Blessed Lady of the shrine is at least as reasonable as to speak of cures wrought by the sug. gestions and influences of Dr. $\mathrm{X}$, or Prolessor $\mathrm{Z}$, as effected by them.

Generally speaking, cures such as these at Lourdes are granted to faith and prayer, and for this reason, in places where faith and prayer abound, they are more likely to occur than where and when faith and prayer are not. "Further," writes Newman, "as faith and prayer obtain miracles, so still more commonly do they gain from above the ordinary interventions of Providence; and as it is often very difficult to distinguish between a providence and a miracle, and there will be more providences than miracles, hence it will happen that many occurrences will be called miraculous which strictly speaking are not such, and not more than providential mercies, or what are called 'graces' or feavours.'

It is this which is so well exemplified at Lourdes. The mere "action of mind on body" does not fully account for what we there find. It is a matter of everyday experience that many arrive with the confident expectation of obtaining relief who in the result receive no material benefit; whilst, on the other hand, there are many instances of persons who have been actually cured who had no hope of being so, and who had come simply to satisfy the importunity of friends. To explain this I may perhaps be allowed to adopt the words of my brother, the late Dr. J. R. Gasquet, who for some weeks in the year 1894 studied the cures at Lourdes, together with Dr. Boissarie, in the Bureau des Constatations Médicales, where all the cases are examined and the evidence sifted. He says : "To say there is nothing remarkable about them, and that they are simply instances of suggestion carried out on a large scele, is merely to provoke the retort: 'Why, then, do you not treat your own patients with equal success?' ... I do not believe that this, that is, formal hypnotic suggestion, is the whole account of the matter. I believe that contact with the supernatural, not only at Lourdes, but in every place where men call for the help of their Creator, may produce much greater effects than ordinary suggestion or auto-suggestion can accomplish. Such effects would be produced through the influence of the mind on the body; and no argument could be based on individual cases, each of which might be paralleled among instances admitted natural. But if the environment of patients visiting Lourdes be borne in mind, it will appear very improbable that the kind and degree of suggestion existing there should produce so many complete and permanent cures, even of purely nervous ailments. Nor will this seem antecedently unlikely tr theists, who will be prepared to admit that prayer has a superhuman efficacy to change and renew the moral and spiritual nature of man. Those who grant so much will hardly think it unreasonable to believe that such an action may sometimes overflow into the body, which they know to be so intimately connected with the mind." 1

But besides the cures, which to a greater or less extent may be considered as brought about by the action of the mind on the body, there are a great number of cases which cannot be explained in this way, at least in the present state of medical and physical science. In all his experience at Salpêtrière, Frofessor Charcot, when he looked for cures to parallel those recorded at Lourdes, had to confess that he could find none in his vast clinic. Instances of such cases may be found in all the books dealing with Lourdes from the point of view of the cures. Dr. Boissarie, whose skill and honesty cannot be doubted, has given a large mass of medical testimony which may be tested by any one interested in these matters. The case of one Gabriel Gargam, set forth in a volume entitled, Lourdes : a History of its Apparitions and Cures, by Georges Bertrin (Kegan Paul, 1908), is one that can be easily verified with very little trouble. Briefly the case is as follows: On December 17th, 1899, Gargam was seriously injured in a railway accident. The Orleans Railway Company being sued for damages, a medical report of December 19th, 1900, declared that the injury "constituted a permanent infirmity, hardly susceptible of improvement, and more likely to terminate fatally." Later a further complication ensued, and gangrene of the feet declared itself. The suit against the company was still pending, and the doctors employed by the Orleans Railway, having seen Gargam, advised the company to offer him a pension of 3000 frencs. The civil courts on February 20th, 1901, characterized the offer as "ridiculous in view of the lamentable condition of the patient," and condemned the railway company to pay him an annual pension of 6,000 francs for life, and an indemnity of 60,000 francs.

The civil courts thus recognized the fact that Gargam was a hopeless invalid for life. The agent of the company went still further, and, having visited the patient and examined the medical reports, advised the railway authorities to offer a payment of 12,000 francs annually in place of the 60,000 francs indemnity, since "Gargam was certain to die soon."

The company refused to pay anything and appealed to the Bordeaux courts, which, however, not only decided in favour of the injured man, but ordered the arrears of pension from the day of the accident to be paid to him. So far the whole medical history of the case had been examined and re-examined in the most public manner possible. Growing worse daily, Gargam was finally persuaded by his friends to allow himself to be carried to Lourdes, at the time of the national pilgrimage, although for years he had not been a practising Catholic and made no secret of his want of faith. For more than 1 Studies: The Cures at Lourdes, p. 322. 
eighteen montbs he had not left his ked at the hospital; the lower portion of his body was as good as dead; he fainted at the least movement, and could only be fed with difficulty by an oesophageal tabe. In what was to all appearances a dying condition, Gargam reached Lourdes, and was carried on a stretcher to the shrine. Many of the spectators publicly protested against his being allowed to remain there, as his death in public, which seemed imminent, would have a bad effect on other invalids. Such was the state of the unfortunate man when, during the blessing of the sick by the Blessed Sacrament, he was instantly cured. Immediately after he was taken to the Medical Office to be examined. "His entrance into the office," says Dr. Boissarie, "was one of the most touching sights we ever beheld. Sixty doctors were present, counting hospital surgeons, professors, foreigners; also many representatives of papers, believers and sceptics." The medical examination made the following day proved that M. Gargam was cured, and that although signs of sores recently healed were visible upon the body, the gangrene of the feet had suddenly disappeared. Strength rapidly returned, and to.day M. Gargam frequently spends hours in helping to carry the sick who come to Lourdes in search of relief from their sufferings and maladies at the shrine where he was made whole.

The cure here briefly set forth, and which ai the time was told in the columns of the Daily Mail by a Jewish eye-witness, may be paralleled by many other similar cases. The publicity, however, of the previous history of the Gargam case, and the fact that the man himself may generally be seen engaged in the work of helping the sick at Lourdes at the present day, makes this a case that can easily be inquired into by anyone who will take the trouble to search into the truth of the facts. Other recorded cases, indeed appear to me to be, if possible, even more extraordinary and incapable of any satisfactory natural explanation. Such would be the instantaneous union of bones which had long been broken, and the ends of which had remained separated by a considerable distance. Science would, I believe, require a considerable period of time to effect the union, even if after a long period it would allow the possibility of bringing the ends together at all. Also, I fancy, most people would allow that no mental suggestion, however powerful, would avail to effect a radical cure of this kind in a fow instants.

In view of the constant progress of scientific knowledge, it is quite possible that it might be necessary to qualify former judgements on cures of this kind. The phrase "as far as we know at present" is always usefully appended to a judgement on these matters. Many things which to our forefathers would have appeared impossible are now shown to have a natural explanation. It is for this reason that the official attitude of the Church towards the miraculous is one of extreme caution, and it is this spirit which prevails at Lourdes. The cures there are certain, and the fullest investigation is welcomed, for to us Catholics, whatever be the explanation of how the cure is effected, the supernatural cause is the spirit of the place and the intercession of the Blessed Mother of God.

\section{FAITH HEALING AND MIRACLES.}

By the Rev. Herbert Thurston, S.J.

"OF the miracles of our Lord," says Sir Clifford Allbutt, in his article entitled "Reflections on Faith Healing," "we shall agree that this is not the place to speak." Sir Clifford's motive in counselling this reticence is no doubt one which all will regard with respect, but it is difficult for an advocate of the reality of modern miracles to treat such phenomena altogether apart from what must be held to be their warrant and their prototype in the New Testament. It has been well said by Sir J. R. Seeley in Ecce Homo :

Miracles play so important a part in Christ's scheme, that any theory which would represent them as due entirely to the imagination of His followers or of a later age destroys the credibility of the documents not partially but wholly, and leaves Christ a personsge as my thical as Hercules. 1

1 Ecce Homo, first edition, p. 43, and see this whole chapter on "Christ's Credentials."
There is no documentary theory of the Gospels which can eliminate the element of miracle from the life of our Lord. No modern critic has professed to discover an Ur.Markus or anything of the sort in which we find a portrait of Christ not yet embellished with signs and wonders. Even Professor Adolf Harnack, whom none can accuse of ultra-conservatism, not long since astonished the agnostic world by announcing his belief that the third Gospel was written by Lake the physician; substantially as we have it now, about the year 80, while it is undis puted that several of St. Paul's epistles with their fally developed belief in the Resurrection are considerably older than this. thIardly seems too much to say that Christianity as a moral system is founded on a belief in Christ's miracles. Yet many even of those who take only a philosophical interest in such discussions will shrink from the further conclusion that the moral reformation which Christianity has introduced and the heroism it has engendered were built upon nothing better than a lie.

Strong, then, as our reluctance may be to admit of any departure from the uniformity of Nature's laws, there are not less motives on the other side to lead the thinker who looks back reverently upon the history of the world, and whose own past mistakes have taught him that overconfidence is one of the greatest enemies of all true know. ledge, to pause before he passes summary judgement upon the character of alleged miracles of healing. Writing for such an audience as are likely to come across this intrasion into the pages of a professional journal of one who is medically speaking a layman, I am hardly disposed to ask for more than delay. I plead for arrest of judgement. I ask that the medical critic should not, after a perusal of Zola's Lourdes on the one hand, or of Huysmans's volume ${ }^{2}$ on the other, believe that he has before him the materials for a final conclusion. The wiser philosopher, I submit, will distrust his power of arriving at a safe decision until he is in full possession of the evidence. One recognizes the immense pressure of work and the vast competition of interests in modern conditions of life; but, if I may say it, with all respect for the many eminent authorities who have written of faith healing in the Journal of June 18th, they do not seem to have acquired their information about Lourdes from the best sources. The work of M. Georges Bertrin, for example, Histoire critique des événements de Lourdes, which provides much the most satisfactory general account, has not, I think, been mentioned by any one. ${ }^{3}$ I might add that the majority of the volumes published about Lourdes, not even excepting those of Dr. Boissarie, the President of the Bureau des Constatations, have been written rather for the edification of Catholics, who already believe, than as a presentment of the case for the scientific and the sceptical. This constitutes a special reason for deprecating a too precipitate judgement. The systematic collection of evidence will, no doubt, be very much aided by the canonical investigations which the bishops have recently been directed to make, but so far the scientific discussion of the facts, hampered as it is by immense difficulties in the matter of certificates, etc., has only been possible in a few of the more striking cures.

I plead, then, that the question of modern miracles be approached in a practical spirit, and I cannot but believe that many members of the medical profession who really retain an open mind must already be profoundly impressed by the element of mystery with which they are so often brought into contact in their observations of disease and its cure. Has any one yet offered a satisfactory explana. tion of the latter-day prevalence of appendicitis? Are the successes of so many unorthodox systems of treatment, often, it would seem, fundamentally at variance with the teachings of authorized medicine-homoeopathy, for example, or hydropathy, and more particularly the latest comer, osteopathy 4 -quite ade. quately accounted for? Is any trustworthy analysis available of the causes which underlie the astonishing

${ }^{2}$ Les foules de Lourdes, a work marked by all the exaggerations of the artistic temperament.

3 The excellent English translation of this work by Mrs. Philip Gibbs unfortunately suffers from the omission of valuable note ontrined in the original.

Fow would credit the developments of osteopathy in America. It appears that to total number of graduates in osteopathic colleges in Was 3,946 . as compar expensive menuals of osteopathic treatment are now published in the country. 